\title{
How Physician Perspectives on E-Prescribing Evolve over Time
}

\section{A Case Study Following the Transition between EHRs in an Out- patient Clinic}

Erika L. Abramson 1,2,3; Vaishali Patel ${ }^{4}$; Elizabeth R. Pfoh5; Rainu Kaushal1,2,3,6

${ }^{1}$ Department of Pediatrics, Weill Cornell Medical College, New York, NY; ${ }^{2}$ Department of Healthcare Policy and Research, Weill Cornell Medical College, New York, NY; ${ }^{3}$ New York-Presbyterian Hospital, New York, NY; ${ }^{4}$ US Department of Health and Human Services, Office of the National Coordinator, Washington, DC; ${ }^{5}$ Department of General Internal Medicine, Johns Hopkins School of Medicine, Baltimore, MD; ${ }^{6}$ Department of Medicine, Weill Cornell Medical College, New York, NY

\section{Keywords}

Physician perspective, EHR, transition, e-prescribing

\section{Summary}

Background: Physicians are expending tremendous resources transitioning to new electronic health records (EHRs), with electronic prescribing as a key functionality of most systems. Physician dissatisfaction post-transition can be quite marked, especially initially. However, little is known about how physicians' experiences using new EHRs for e-prescribing evolve over time. We previously published a qualitative case study about the early physician experience transitioning from an older to a newer, more robust EHR, in the outpatient setting, focusing on their perceptions of the electronic prescribing functionality. Objective: Our current objective was to examine how perceptions about using the new HER evolved over time, again with a focus on electronic prescribing.

Methods: We interviewed thirteen internists at an academic medical center-affiliated ambulatory care clinic who transitioned to the new EHR two years prior. We used a grounded theory approach to analyze semi-structured interviews and generate key themes.

Results: We identified five themes: efficiency and usability, effects on safety, ongoing training requirements, customization, and competing priorities for the EHR. We found that for even experienced e-prescribers, achieving prior levels of perceived prescribing efficiency took nearly two years. Despite the fact that speed in performing prescribing-related tasks was highly important, most were still not utilizing system short cuts or customization features designed to maximize efficiency. Alert fatigue remained common. However, direct transmission of prescriptions to pharmacies was highly valued and its benefits generally outweighed the other features considered poorly designed for physician workflow.

Conclusions: Ensuring that physicians are able to do key prescribing tasks efficiently is critical to the perceived value of e-prescribing applications. However, successful transitions may take longer than expected and e-prescribing system features that do not support workflow or require constant upgrades may further prolong the process. Additionally, as system features continually evolve, physicians may need ongoing training and support to maintain efficiency.

\section{Correspondence to:}

Erika Abramson, MD, MS,

Departments of Pediatrics and Healthcare Policy and Research,Weill Cornell Medical College

525 East $68^{\text {th }}$ Street, Rm M 610A

New York, NY 10065

Tel: 212-746-3929, Fax: 212-746-3140

Email: err9009@med.cornell.edu

\author{
Appl Clin Inform 2016; 7: 994-1006 \\ http://dx.doi.org/10.4338/ACI-2016-04-RA-0069 \\ received: August 3, 2016 \\ accepted: September 17, 2016 \\ published: October 26, 2016 \\ Citation: Abramson EL, Patel V, Pfoh RE, Kaushal R. \\ How physician perspectives on E-prescribing evolve \\ over time: A case study following the transition be- \\ tween EHRs in an outpatient clinic. Appl Clin Inform \\ 2016; 7: 994-1006 \\ http://dx.doi.org/10.4338/ACl-2016-04-RA-0069
}




\section{Background and Significance}

Widespread adoption of commercial EHRs with e-prescribing capability is occurring [1-4]. Many physicians and healthcare organizations have transitioned from paper records to EHRs. Others have transitioned from locally-developed to certified commercial systems, or upgraded from older to newer commercial system versions, to be eligible for incentives, increase interoperability, and utilize vendor-based product development and support [5-7]. Transitioning to a new EHR is often resource intensive and expensive, and not all transitions are successful [8].

E-prescribing is a key functionality of most EHRs. Understanding the physician perspective on use of commercial EHRs for e-prescribing can help inform the development and design of systems and features that better meet physicians' needs and workflow. Understanding the experience of physicians over time can also help organizations better manage physician expectations. This is critical as despite the many positive benefits associated with health information technology (HIT), physician dissatisfaction remains high among some providers and meeting the needs of end users is important to facilitate its successful use [9].

We previously conducted two quantitative studies and a qualitative study examining physicians' experiences with medication prescribing in the outpatient setting after transitioning between an older, locally-developed system and a newer, commercial EHR (Epic 2010) [10-12]. Our quantitative work showed a significant reduction in prescribing errors only in the second year post-implementation, despite the more robust clinical decision support (CDS) in the new EHR. From a qualitative perspective, at one-year post-transition, we found that even for experienced physicians, transitioning was difficult. Physicians felt the commercial system was overly complex, reducing their prescribing efficiency. Physicians also did not perceive that medication errors were reduced, despite having robust CDS to aid with prescribing.

\section{Objective}

These perceptions, however, may be specific to the early transition period. It is possible that with increasing familiarity and iterative refinements to the system, perceptions may change. While there is a growing body of literature examining physician perspectives on using a commercial EHR for prescribing, there is limited literature assessing physician perspectives on prescribing after transitioning between EHR systems or following such a group over time [13-21]. The objective of this case study, conducted two years post transition, was to see how physicians' perceptions and experiences with prescribing evolved after prolonged system use.

\section{Methods}

\subsection{Design and Participants}

We conducted semi-structured interviews of physicians, with a focus on their e-prescribing experiences, two years post-transition. We probed specifically on how experiences evolved over time and followed up themes that emerged during the first round of interviews at one-year post-transition ( $>$ Table 1 for sample questions).

To participate, faculty had to work $75 \%$ time or more and at least 2 clinic sessions per week at the academic-affiliated, urban hospital-based adult internal medicine outpatient clinic. The research team that conducted the interviews and performed data analysis was a multi-disciplinary team consisting of physicians and non-physicians, with expertise in health services research, patient safety, informatics and qualitative methods. A team of outside expert qualitative researchers provided oversight to ensure methodological rigor.

Interviews were audio-recorded and professionally transcribed. Participants received a \$200 cash incentive. Prior to interviews, we administered a brief survey to obtain demographic information and information technology experiences. 
We also performed a quantitative analysis of prescribing errors at one year and two-years posttransition. These results have been published separately $[10,12]$. Physicians did not have individual access to this data, nor did they have knowledge of the results prior to interviews. We received Institutional Review Board approval from Weill Cornell and physician consent.

\subsection{Background and Setting}

\section{Transition between Systems}

In previously published manuscripts, we described the transition between systems that occurred in April 2008 [10-12]. Briefly, the information systems team conducted a large scale, intensive effort to transition physicians, including transferring medication data between systems, providing mandatory user training, and minimizing schedules after go-live. Formal workflow analyses were conducted prior to aid in the development of customized templates, preference lists (prioritized lists of frequently used orders) and order sets (bundled orders for particular conditions).

\section{Older System}

The older system was a locally developed, uniquely customized, PC-based EHR implemented in 1993. The system had free text electronic progress notes, electronic order entry, laboratory result viewing, and clinical messaging. There was no direct transmission of prescriptions to pharmacies. The only CDS was default formulations and provision of generic alternatives. The medication database was managed by the developer but allowed free-text "work-arounds."

\section{Newer System}

The newer system is Epic 2010. In addition to the features of the older system, the newer system has much more robust CDS for medication ordering, including default dosages, default patient instructions, and allergy and drug-drug interaction alerts. The medication database and CDS logic is derived from a third party. All drug-drug allergy alerts are classified as high severity, while the drugdrug interaction alerts are broken into three severity categories by the vendor. The alerts can be adjusted for sensitivity, such that only the highest or two highest categories are displayed.

The system also allows physicians to customize their own medication preference lists (for frequently used medications) as well as medication "sig" instructions. There are also system shortcuts such as "control O" to take physicians directly to the ordering screen. The system can directly transmit prescriptions to pharmacies - a feature that became both available and widely utilized between one and two years post-implementation.

\section{Changes to the New EHR}

After the first round of interviews, a number of refinements and fixes were made to the EHR as a result of regulatory requirements and feedback from physicians. To target alert fatigue, alert firing was limited to only the highest severity alerts, rather than medium and high severity. Tall man lettering was added to certain medications to highlight, using capital letters, differences between drugs with similar names. In addition, due to new regulatory requirements, prescribers were required to separately enter the quantity and unit to be dispensed for a medication by choosing from two separate drop-down menus. This was known as "discrete dispense." However, there was no support to guide prescribers as to common quantities and units typically carried in pharmacies, and no free text option to write "dispense quantity sufficient," which was common practice and allowed pharmacists to drive dispensing of medications based on their knowledge of pharmacy stock and drug packaging. Minor updates to the medication database and CDS made by the vendor were incorporated on an ongoing basis. Email notifications were sent to physicians informing them of minor changes; brief training sessions were held by IT for major changes such as the introduction of discrete dispense.

\section{Data Analysis}

For the initial interviews at one-year post transition, we performed data analysis using a grounded theory approach in which theme development is guided by the interviewees' own words [22]. For two-year interviews, we began with the list of codes developed in the first series of interviews, and using the constant comparative method, added new codes to describe emerging concepts [23]. 
When themes overlapped, we compared sentiments found in the initial interviews to themes found in the follow-up interviews.

Initial coding of transcribed interviews was done in pairs (pairing a clinician and non-clinician), with discussion until coding consistency (defined as $90 \%$ or more agreement) was achieved. Thereafter, coding was performed independently. After coding half the data, we reviewed independent coding, resolving through discussion any discrepancies, and identified an initial set of patterns and themes. We then coded the remainder for verification and to ensure no additional themes emerged. We used member checking (soliciting feedback from research participants) to help ensure the credibility of our findings (EA presented preliminary findings at a faculty meeting for group discussion). We used ATLAS.ti software.

\section{Results}

\subsection{Physician Characteristics}

Eighty-seven percent of eligible physicians (13 of 15) participated. Eleven of 13 had participated in initial interviews at one year. The other two physicians had both worked at the clinic prior to implementation of the new EHR. Interviews lasted between 25 and 30 minutes. Demographic and practice characteristics are presented in Table 2. Most physicians were very experienced users of electronic prescription writing and were comfortable utilizing new technology.

\subsection{Key Findings}

Five themes emerged ( $\$$ Table 3 ). Four themes related directly to themes identified at one year: efficiency and usability, effects on safety, ongoing training requirements, and customization. One theme was new: competing priorities for the EHR. For the first 4 themes, we have included key findings and quotes from our previously published initial work to more directly highlight the evolution of perspectives over time [11].

\section{Theme: Efficiency and Usability}

At one year we had found that physicians felt the new system required frequent mouse clicks and multiple steps to complete even simple tasks, decreasing efficiency and usability. It was only closer to two years that most perceived they were back to baseline levels of efficiency, although this was due to greater familiarity with the new system, rather than the design of the system itself. As one physician stated: "(The system) is complex. But, you know, you learn it, and it doesn't seem that hard after you learn it."

As had been expressed in interviews at one year, most physicians felt the new system remained overly complex: "It remains a very cumbersome and over-engineered, point and click happy system." Many complained about the very long medication lists, making it difficult to find specific formulations: "It is very hard to find medications. Even really common medications.... It is a very big problem." This was compounded by a lack of flexible search engines: "If you inadvertently misspell (a medication), there is no match."

Despite these complaints, the ability to directly transmit prescriptions to pharmacies was seen as "a phenomenal convenience." In particular, this greatly facilitated ordering of refills, a previously very time consuming task: "(Comparing the old and new system), in terms of their ease of ordering, their default doses, directions, their drug alerts ... I would say that the single reason (I am) satisfied with the new system is e-prescribe." Physicians, however, expressed frustration that the task of verifying and entering pharmacy information often fell to them.

\section{Theme: Effects on Safety}

At one year we found that most physicians did not feel the new EHR decreased prescribing errors. Two years post implementation, this perception continued to hold: "Well, compared to somebody's handwriting, it's much more safe... But, then again, compared with (the old system) I'm not sure it's any different." 
While physicians appreciated the reduction in alerts between years one and two, most continued to endorse that there were far too many, desensitizing clinicians to those alerts that were of actual clinical importance: "If there is really a dangerous interaction, a dangerous allergy kind of alert that is useful. That doesn't happen often. $90 \%$ of the time you override it." The frequent alerts that required overriding also hindered prescribing efficiency. Tall man lettering, which was a new feature, was felt to enhance safety, although some felt it was necessary only because the drop-down medication lists were too long.

\section{Theme: Ongoing Training Requirements}

Due to frequent system refinements and fixes, physicians were required to make adjustments to their workflow frequently. Some were minor - such as becoming accustomed to different ways information was displayed; others involved significant changes in how prescriptions had to be written (such as discrete dispense). These continuous changes and the need to re-adapt workflow detracted from the efficiency gains physicians were making: "It took quite a while for me to learn the system. But with each rollout, it's taking more work." Physicians were mixed on whether they preferred small changes frequently versus grouping small changes together to have more significant but less frequent modifications.

Even two years post-implementation, some physicians were meeting on a monthly basis to try and better standardize workflow. This was felt to be particularly important for the housestaff being supervised by attendings, who were confused by the different ways they were shown to do a single task: "You can do one thing twelve different ways and then everyone does it differently. We go over how we've been writing prescriptions. We've standardized our work flow, so it's... better."

\section{Theme: Customization}

Although the new system had many features designed to improve efficiency, including short cuts and customization options, these features remained underutilized. At one-year post-implementation, we found that most physicians were not aware many of these features existed. At two years, physicians were generally aware of their existence but needed retraining: "I'd like to have somebody actually go through them....there are some additional tricks or modifications that would be nice to be taught." More than half of the physicians interviewed, however, stated, that even with training, all but the simplest system shortcut features would either be too difficult to customize themselves ("Only a savvy user... (can) tailor the system to what makes sense for them") or would be too timeconsuming to configure.

\section{Theme: Competing Priorities within the EHR}

Clinicians expressed frustration that the new EHR was clearly designed to meet multiple purposes, including supporting physician documentation and ordering for generalists and subspecialists, meeting regulatory requirements, and facilitating billing. This resulted in a clunky system, rather than one that was well designed to primarily support physician use: "The system is not customized to just us and it shows."

Certain regulatory requirements, such as discrete dispense, were particularly problematic for physicians when integrated into the EHR: "I understand that (the vendor) didn't want discrete dispense but it is so difficult." With discrete dispense, for example, physicians were often not familiar with the formulations or quantities typically dispensed for medications (a domain previously of pharmacists). Physicians had to spend extra time asking colleagues or calling pharmacies directly.

\section{Discussion}

This case study provides important perspective on how physician expectations, needs, and sentiments regarding use of an EHR for prescribing in the ambulatory setting evolve over time following the transition between EHR systems. We found that even for very experienced e-prescribers, it took nearly two years before most perceived they were back to baseline levels of prescribing efficiency. The rigidity and complexity of the prescribing application, use of the EHR for many different purposes, and constant refinements to the prescribing application, all contributed to this perception. 
Many system features designed to improve prescribing efficiency remained underutilized either because physicians needed retraining now that they had mastered the system basics, or because customization was too difficult and time consuming. Direct transmission of prescriptions to pharmacies was the one feature that was perceived as so successful in improving speed and efficiency that it outweighed many challenges.

While we anticipated that familiarity with prescribing through the new EHR would improve over time and result in better efficiency, we were surprised at how long it took these experienced physicians to perceive they were back to baseline levels. One study of primary care practices found patient volume and productivity decreased in the first 12 months following EHR implementation and was still $4 \%$ below baseline at 12 months [24]. A qualitative study of providers newly adopting an EHR found that they were still facing challenges learning how to use the system after 2 years. [25] However, providers in both studies were transitioning from paper to an EHR, where one might have expected the decreases in productivity to be more profound. Nonetheless, a recent study of physicians transitioning from a locally developed to commercial EHR found that positive perceptions of the new system, including on workflow and efficiency, were generally below baseline at the two year mark, corroborating our findings.[19] However, this study did not explore e-prescribing specifically and was quantitative in nature, limiting the ability to probe in depth the reasons behind those sentiments.

A partial explanation for our providers' perceptions may be the ongoing iterative changes that frequently disrupted efficiency gains and frustrated users, some which were a result of system fixes and others a result of regulatory requirements. Studies of best implementation practices have emphasized the need to educate physicians about anticipated changes to workflow and what the future will look like [26]. A qualitative study assessing EHR implementation proposed using the five stages of grief model to categorize the changes involved as physicians adopt a new EHR, including loss of efficiency and old workflow [27]. Helping physicians to have realistic expectations about the time it may take to achieve past levels of efficiency for key tasks like prescribing may help mitigate initial and ongoing frustrations.

Of course, system features that are poorly designed will reduce efficiency and necessitate ongoing changes to the system, highlighting the need for products to be designed using systems engineering principles that focus on the needs of end users. An example from this study is discrete dispense, which was a regulatory requirement and therefore needed to be implemented, but created significant difficulties for physicians. Providing CDS to aid providers who were generally unfamiliar with typical quantities and units for many products may have mitigated the difficulties they encountered with the rollout of this feature. Our providers were all experienced users of EHRs for prescribing and most were comfortable using new technology. Arguably, they are a group that would be best equipped to deal with constant changes to the prescribing application and yet their perceived difficulties were still substantial.

As was the case in our and other studies, speed in performing tasks is particularly important to clinicians and thus optimizing a few key features that can greatly improve physician efficiency may help to garner enthusiasm for an otherwise negatively perceived system [28-30]. This was the case in our study with direct transmission of prescriptions to pharmacies, which was such a convenience to physicians that it outweighed many of the other negatively perceived aspects of the prescribing application. Notably, usability issues are increasingly recognized not just for their effects on efficiency, but safety as well. The American Medical Informatics Association (AMIA) has even created a Task Force on Usability to help drive improved quality and safety through enhanced EHR usability [31].

Our study also highlights important lessons with regard to ongoing training and information technology needs for physicians following the transition to a new system. We were surprised by how few physicians reported using features designed to improve individual-level efficiency related to prescribing, including simple "control commands" that eliminated the multiple mouse clicks physicians frequently disliked. Thus, it may be that once physicians are familiar with the basics of a system, organizations should focus on helping physicians optimize their own individual workflow. This can include training sessions on system short cuts, devoting information technology staff time to performing individual customizations of features such as preference lists, and using staff meetings to share knowledge and standardize practices.

Lastly, despite the efforts made by the information technology group to reduce alerts, alert fatigue remained an ongoing problem. Alert fatigue, in which physicians become desensitized to alerts be- 
cause of the large number of alerts presented to them, is a well described phenomenon [32-35]. Most physicians we interviewed continued to feel that the new system presented so many irrelevant alerts that the clinically relevant ones were easily overlooked. Thus most physicians did not perceive the new system as reducing errors, despite the fact that our quantitative study found that prescribing errors were significantly reduced by two years post-implementation [12]. Several recent studies have proposed criteria to better evaluate which types of alerts should be prioritized [36-38]. Adding comments about the usefulness of alerts and tracking alert overrides may also help guide optimization of alert firing. Better optimization of alert firing in order to reduce alert fatigue by physicians will be essential to realize the potential of CDS to improve prescribing safety.

\subsection{Policy Implications and Recommendations}

The 2015 edition of certified EHR technology requires that certified systems meet the National Institute of Standards and Technology usability criteria and test EHR user interfaces for tasks impacting patient safety [40]. Our research supports these recommendations, highlighting the growing recognition that EHR features need to be better designed to improve usability, physician satisfaction, and ultimately patient safety $[39,40]$. In addition, our findings suggest that physicians need ongoing training and technical assistance to maintain or improve efficiency for key tasks such as prescribing. Providing retraining at 6-12 months, with a focus on features meant to improve efficiency (such as system shortcuts), may greatly benefit physicians who can now better absorb these tips after gaining some level of familiarity with the new system. Better systems and better training would hopefully substantially shorten the degree and time of perceived inefficiency experienced by providers.

Given the very busy workload of physicians in outpatient practice, our findings suggest that asking physicians to take the time to self-customize prescribing-related features such as preference lists is unrealistic, and organizations or vendors may need to take on this workload. Greater sustained technical assistance over time has been associated with reaping greater quality benefits. For the physicians in our study, a team of clinical informaticists has been working internally and with the vendor to improve the prescribing application and train providers. However, this support is not available to the majority of physicians. Federally funded programs, such as The Regional Extension Center (REC) Program, have provided EHR technical assistance and support to over 100,000 small and rural primary care physicians nationwide to assist them with their transition to adopt and meaningfully use EHRs [41]. As the REC program ends, addressing the continuing needs of physicians for technical assistance will be important. Research has shown physicians find the support of RECs helpful and want ongoing assistance even years after adoption [42]. Whether, in the future, this support will be provided by the vendors in a bid to increase competitiveness in the market, internally through informatics teams at large organizations, or through new local or federally funded initiatives remains to be seen.

\subsection{Limitations}

Our case study has several limitations. First, we studied only a small number of physicians practicing in the outpatient setting and using a single EHR for prescribing, limiting generalizability. In addition, the transition occurred several years ago. However, Epic is one of the most widely utilized commercial systems and changes by the vendor, while ongoing, have not created such a significantly different product. Third, we did not repeat field observations of physicians using the new EHR, reducing our ability to corroborate physician perceptions. We also did not perform measures of efficiency and speed.

\section{Conclusion}

Our case study provides an important, in-depth look at physician perceptions on prescribing over time following the transition between EHRs in the outpatient setting. Given widespread commercial EHR adoption, understanding the physician experience with the e-prescribing functionality, a key feature of commercial EHRs, can allow organizations to better manage expectations and work with 
physicians to maximize their use of and satisfaction with this feature. Of greatest importance to physicians appears to be the ease with which key functions can be performed. Thus features of the e-prescribing application which are simple and improve efficiency are likely to be preferred and should be a consideration for vendors. Physicians may need additional training and support long after the transition to increase use of shortcuts and customization options that will improve prescribing efficiency. Finally, it may take several years for even experienced e-prescribers to become comfortable prescribing with a new system. Having realistic expectations about this timeframe will be important messaging at both an individual and organizational level as the adoption or transition to a new EHR occurs.

\section{Multiple Choice Question}

1. Following the transition between electronic health record systems, when do most providers report achieving prior levels of efficiency with regard to electronic prescribing?

- a. Immediately after the transition

- b. 6 months after the transition

- c.12 months after the transition

- d.1.5 years or longer after the transition

Correct Answer - D - Even for experienced e-prescribers, our study, along with limited other literature on this topic, suggests that perceived decreases in efficiency last long after "go-live" of the new system. This appears to be true both for providers transitioning from a paper to an EHR for the first time, as well as providers transitioning between EHR systems.

Perceived decreases in efficiency may be occurring for several reasons, related to suboptimal user interfaces and features within the EHR product, the complexity of EHR systems that are designed to support the work of multiple users, rather than simply clinicians, and training and technical support that is primarily focused immediately on the go-live period, rather than after a period of sustained use.

\section{Clinical Relevance Statement}

This article provides an in-depth view of the perceptions of physicians who transitioned from an older to a newer, more robust EHR in the outpatient setting, with a focus on the electronic prescribing functionality. Transitioning is a common issue faced by a growing number of physicians in light of federal incentives promoting adoption and meaningful use of EHRs. In addition to ensuring that prescribing-related features of EHRs are optimally designed to support clinical workflow, making sure providers have realistic expectations about the time to achieve prior levels of prescribing efficiency, and providing ongoing training, particularly after the six-month mark, may greatly help reduce frustration.

\section{Conflicts of Interests}

None of the authors have any financial or other conflicts of interest.

This project was supported by AHRQ (R18HS017029), Rockville, MD.

\section{Protection of Human Subjects}

The study was performed in compliance with the World Medical Association Declaration of Helsinki on Ethical Principles for Medical Research Involving Human Subjects, and was reviewed by the Weill Cornell Medicine Institutional Review Board.

\section{Acknowledgement}

The authors thank Drs. Curtis Cole and Adam Cheriff for their support in the conceptual design of this project. The authors thank Dr. Joan Ash and Arwen Bunce, MA for providing external expertise as to the qualitative methodology utilized in this study. The authors also thank Alison Edwards, MS for statistical contributions. 
Table 1 Sample Interview Questions

\begin{tabular}{l|l|}
\hline Topic & Introductory Question(s) \\
\hline $\begin{array}{l}\text { Experience with the new } \\
\text { EHR over time }\end{array}$ & $\begin{array}{l}\text { How does your experience with the new EHR for prescription writing compare } \\
\text { with one year ago? }\end{array}$ \\
\hline Workflow & $\begin{array}{l}\text { How if at all has your workflow changed using the new EHR compared with one } \\
\text { year ago? }\end{array}$ \\
\hline System Modifications & $\begin{array}{l}\text { There are aspects of the computerized prescription writing component of the new } \\
\text { system that have changed in the past year. Tell me your thoughts about the cur- } \\
\text { rent features. }\end{array}$ \\
\hline Safety & What effect do you feel the new system has had on safety over time? \\
\hline Training & What if any training needs do you have currently?
\end{tabular}

Table 2 Provider Demographics

\begin{tabular}{|c|c|}
\hline \multicolumn{2}{|l|}{ Provider Characteristics } \\
\hline Female gender, $\mathrm{n}(\%)$ & $6(46)$ \\
\hline Years since medical school, median (min-max) & $21(6-32)$ \\
\hline Age, median (min-max) & $53(31-57)$ \\
\hline \multicolumn{2}{|l|}{ Information Technology Experiences } \\
\hline \multicolumn{2}{|l|}{ Typing Skills, n (\%) } \\
\hline Very poor & $1(8)$ \\
\hline Poor & $0(0)$ \\
\hline Fair & $2(15)$ \\
\hline Good & $6(46)$ \\
\hline Excellent & $4(31)$ \\
\hline \multicolumn{2}{|l|}{ Frequency of Internet use (personal or professional), n (\%) } \\
\hline Rarely & $0(0)$ \\
\hline Once monthly & $0(0)$ \\
\hline Once weekly & $1(8)$ \\
\hline Once daily & $0(0)$ \\
\hline Several times a day & $12(92)$ \\
\hline \multicolumn{2}{|c|}{$\begin{array}{l}\text { Comfort utilizing new information technologies (e.g., online resources, online x-rays) tc } \\
\text { care for patients, } n(\%)\end{array}$} \\
\hline Very uncomfortable & $1(8)$ \\
\hline Somewhat uncomfortable & $0(0)$ \\
\hline Neutral & $1(8)$ \\
\hline Somewhat comfortable & $5(38)$ \\
\hline Very comfortable & $6(46)$ \\
\hline $\begin{array}{l}\text { Years using ambulatory or inpatient computerized prescription writing sys- } \\
\text { tem, median (min-max) }\end{array}$ & $15(3-20)$ \\
\hline
\end{tabular}


Table 3 Summary of Key Findings with Supporting Comments from Physicians

\begin{tabular}{|c|c|c|c|c|}
\hline Theme & $\begin{array}{l}\text { Key Findings Year } \\
1\end{array}$ & $\begin{array}{l}\text { Example Quotes } \\
\text { Year } 1\end{array}$ & $\begin{array}{l}\text { Key Findings Year } \\
2\end{array}$ & $\begin{array}{l}\text { Example Quotes } \\
\text { Year } 2\end{array}$ \\
\hline \multirow[t]{3}{*}{$\begin{array}{l}\text { Efficiency } \\
\text { and } \\
\text { Usability }\end{array}$} & $\begin{array}{l}\text { Commercial EHR, } \\
\text { while very compre- } \\
\text { hensive, was over-en- } \\
\text { gineered, rigid, and } \\
\text { too complex, in- } \\
\text { hibiting efficiency and } \\
\text { usability }\end{array}$ & $\begin{array}{l}\text { "It is simply too over- } \\
\text { engineered for what a } \\
\text { doctor needs... (our } \\
\text { locally developed sys- } \\
\text { tem) was much more } \\
\text { simple, much more } \\
\text { bare bones.... (now) } \\
\text { it's } 25 \text { bloody mouse } \\
\text { clicks..." }\end{array}$ & $\begin{array}{l}\text { New system still per- } \\
\text { ceived as overly com- } \\
\text { plex, despite in- } \\
\text { creased familiarity of } \\
\text { providers }\end{array}$ & $\begin{array}{l}\text { "It's the way it's basi- } \\
\text { cally designed. It should } \\
\text { be easier. You have to be } \\
\text { so totally meticulous to } \\
\text { find that drug. It's very } \\
\text { exhausting." }\end{array}$ \\
\hline & \multirow[t]{2}{*}{$\begin{array}{l}\text { Providers perceived } \\
\text { productivity as de- } \\
\text { creased with the new } \\
\text { system, even after one } \\
\text { year of use }\end{array}$} & \multirow{2}{*}{$\begin{array}{l}\text { "I'm losing 3-7 min- } \\
\text { utes per patient and } \\
\text { have a similar } 15 \% \\
\text { reduction in produc- } \\
\text { tivity on a daily basis } \\
\text { that I have not yet re- } \\
\text { covered to go to base- } \\
\text { line productivity. After } \\
\text { a year I'm still be- } \\
\text { hind." }\end{array}$} & $\begin{array}{l}\text { Familiarity with the } \\
\text { new system led to im- } \\
\text { proved efficiency over } \\
\text { time but reaching } \\
\text { prior levels of efficien- } \\
\text { cy took much longer } \\
\text { than expected }\end{array}$ & $\begin{array}{l}\text { "I find it faster now, } \\
\text { simply because I know } \\
\text { the system } \\
\text { better....That's really } \\
\text { where the efficiency has } \\
\text { come from." }\end{array}$ \\
\hline & & & $\begin{array}{l}\text { E-prescribing (direct } \\
\text { transmission of pre- } \\
\text { scriptions to the phar- } \\
\text { macy) is the key fea- } \\
\text { ture driving improved } \\
\text { efficiency }\end{array}$ & $\begin{array}{l}\text { "Being able to e-pre- } \\
\text { scribe is great. It's easy. } \\
\text { It makes things much } \\
\text { faster." }\end{array}$ \\
\hline \multirow[t]{2}{*}{$\begin{array}{l}\text { Effects on } \\
\text { Safety }\end{array}$} & $\begin{array}{l}\text { While certain clinical } \\
\text { decision support was } \\
\text { perceived as decreas- } \\
\text { ing errors, the overall } \\
\text { perception was that } \\
\text { safety did not improve } \\
\text { as a result of using a } \\
\text { commercial system }\end{array}$ & $\begin{array}{l}\text { "The additional bene- } \\
\text { fits of (commercial } \\
\text { system) in terms of } \\
\text { searching for drug in- } \\
\text { teractions and toxic- } \\
\text { ities is occasionally } \\
\text { beneficial and more } \\
\text { often annoying." }\end{array}$ & $\begin{array}{l}\text { Providers continued to } \\
\text { feel that the new sys- } \\
\text { tem did not make pre- } \\
\text { scribing safer }\end{array}$ & $\begin{array}{l}\text { "I think that we all were } \\
\text { told that we were doing } \\
\text { this and that it was } \\
\text { going to decrease pa- } \\
\text { tient errors... I think in } \\
\text { the long run we didn't } \\
\text { but in the short term we } \\
\text { caused harm." }\end{array}$ \\
\hline & $\begin{array}{l}\text { Alert fatigue was per- } \\
\text { ceived as a significant } \\
\text { problem with the new } \\
\text { system }\end{array}$ & $\begin{array}{l}\text { "I find (alerts) useful } \\
\text { probably } 25 \% \text { of the } \\
\text { time, and } 75 \% \text { of the } \\
\text { time they're an an- } \\
\text { noyance. I would like } \\
\text { the filter set higher." }\end{array}$ & $\begin{array}{l}\text { Alert sensitivity im- } \\
\text { proved with refine- } \\
\text { ments to the system } \\
\text { but alerts still firing } \\
\text { too frequently }\end{array}$ & $\begin{array}{l}\text { "I have noticed a differ- } \\
\text { ence, but again, when } \\
\text { five (alerts) come up, } \\
\text { and you've got to get } \\
\text { the patients their pre- } \\
\text { scriptions, it's hard to } \\
\text { sort through." }\end{array}$ \\
\hline $\begin{array}{l}\text { Ongoing } \\
\text { Training } \\
\text { Require- } \\
\text { ments }\end{array}$ & $\begin{array}{l}\text { Extensive efforts were } \\
\text { put into training prior } \\
\text { to the transition; } \\
\text { physicians noted the } \\
\text { need for ongoing } \\
\text { training due to exten- } \\
\text { sive system refine- } \\
\text { ments }\end{array}$ & & $\begin{array}{l}\text { Ongoing refinements } \\
\text { to the system made it } \\
\text { necessary to con- } \\
\text { stantly retrain pro- } \\
\text { viders; these refine- } \\
\text { ments impeded pro- } \\
\text { vider efficiency }\end{array}$ & $\begin{array}{l}\text { "And then whenever a } \\
\text { change is } \\
\text { made...suddenly it } \\
\text { slams you to a halt, then } \\
\text { you gotta slow down... } \\
\text { And every prescription } \\
\text { suddenly needs to be re- } \\
\text { written, like we were at } \\
\text { the beginning." }\end{array}$ \\
\hline
\end{tabular}


Table 3 Continued

\begin{tabular}{|c|c|c|c|c|}
\hline Theme & $\begin{array}{l}\text { Key Findings Year } \\
1\end{array}$ & $\begin{array}{l}\text { Example Quotes } \\
\text { Year } 1\end{array}$ & $\begin{array}{l}\text { Key Findings Year } \\
2\end{array}$ & $\begin{array}{l}\text { Example Quotes } \\
\text { Year } 2\end{array}$ \\
\hline \multirow[t]{2}{*}{$\begin{array}{l}\text { Customiz- } \\
\text { ation }\end{array}$} & \multirow{2}{*}{$\begin{array}{l}\text { Providers were not } \\
\text { aware of and were } \\
\text { not using features } \\
\text { such as customized } \\
\text { preference lists/"sig" } \\
\text { instructions or short- } \\
\text { cuts designed to im- } \\
\text { prove efficiency at the } \\
\text { one year mark }\end{array}$} & & $\begin{array}{l}\text { Features designed to } \\
\text { improve provider effi- } \\
\text { ciency (customiz- } \\
\text { ations, short cuts) } \\
\text { were still under-util- } \\
\text { ized }\end{array}$ & $\begin{array}{l}\text { "I don't know how to } \\
\text { have a drug preference } \\
\text { in the system... I am } \\
\text { just beginning to figure } \\
\text { out how to use short } \\
\text { cuts." }\end{array}$ \\
\hline & & & $\begin{array}{l}\text { Many providers ex- } \\
\text { pressed a desire for } \\
\text { "re-training" on these } \\
\text { features designed for } \\
\text { efficiency now that } \\
\text { they were comfortable } \\
\text { with the new system }\end{array}$ & $\begin{array}{l}\text { "In training they did } \\
\text { show me short cuts. The } \\
\text { problem is they trained } \\
\text { me on everything at the } \\
\text { same time." }\end{array}$ \\
\hline \multirow[t]{2}{*}{$\begin{array}{l}\text { Competing } \\
\text { Priorities for } \\
\text { the EHR }\end{array}$} & \multirow[t]{2}{*}{ Not a theme year 1} & \multirow[t]{2}{*}{ Not a theme year 1} & $\begin{array}{l}\text { Providers were frus- } \\
\text { trated that the EHR } \\
\text { was clearly designed } \\
\text { to support multiple } \\
\text { purposes, rather than } \\
\text { primarily for physician } \\
\text { use }\end{array}$ & $\begin{array}{l}\text { "They (should) custom- } \\
\text { ize it to just medicine. } \\
\text { They can do away with } \\
\text { some of the data entry } \\
\text { that is not absolutely } \\
\text { necessary. That's the big- } \\
\text { gest thing." }\end{array}$ \\
\hline & & & $\begin{array}{l}\text { Discrete dispense, a } \\
\text { newly imposed regu- } \\
\text { latory requirement, } \\
\text { was a feature particu- } \\
\text { larly challenging for } \\
\text { physicians }\end{array}$ & $\begin{array}{l}\text { "I can't blame (the ven- } \\
\text { dor) for discreet dis- } \\
\text { pense...that was the } \\
\text { government.... It is just } \\
\text { this new curve ball } \\
\text { which makes us all } \\
\text { slower again." }\end{array}$ \\
\hline
\end{tabular}




\section{References}

1. Health information technology: initial set of standards, implementation specifications, and certification criteria for electronic health record technology. Final rule. Fed Regist 2010; 75(144): 44589-654.

2. Charles D, King, J, Patel, V, Furukawa M. Adoption of Electronic Health Record Systems among U.S. Nonfederal Acute Care Hospitals: 2008-2012. Office of the National Coordinator for Health Information Technology, 2013.

3. Hsiao C-J, Hing E. Use and characteristics of electronic health record systems among office-based physician practices: United States, 2001-2013. NCHS data brief, no 143. Hyattsville, MD: National Center for Health Statistics. 2014.

4. Gabriel M, Swain M. E-prescribing Trends in the United States. The Office of the National Coordinator for Health Information Technology, 2014.

5. Yoon-Flannery K, Zandieh SO, Kuperman GJ, Langsam DJ, Hyman D, Kaushal R. A qualitative analysis of an electronic health record (EHR) implementation in an academic ambulatory setting. Inform Prim Care 2008; 16: 277-284.

6. Cedars-Sinai Medical Center Taps Thomson Healthcare to Improve Clinical Performance and Standards Compliance. Patient Safety and Quality Healthcare Business News. Farmington Hills, Michigan: PR Newswire Association LLC; 2007.

7. Bentley T, Rizer M, McAlearney AS, Mekhjian H, Siedler M, Sharp K, Teater P, Huerta T: The journey from precontemplation to action. Transitioning between electronic medical record systems. Health Care Manage Rev 2014.

8. Gettinger A, Csatari A. Transitioning from a Legacy EHR to a Commercial, Vendor-supplied, EHR: One Academic Health Systems Experience. Appl Clin Inform 2012; 3: 367-376.

9. Buntin MB, Burke MF, Hoaglin MC, Blumenthal D. The benefits of health information technology: a review of the recent literature shows predominantly positive results. Health Aff (Millwood) 2011; 30: $464-471$.

10. Abramson EL, Malhotra S, Fischer K, Edwards A, Pfoh ER, Osorio SN, Cheriff A, Kaushal R. Transitioning between electronic health records: effects on ambulatory prescribing safety. J Gen Intern Med 2011; 26: 868-874.

11.Abramson EL, Patel V, Malhotra S, Pfoh ER, Nena Osorio S, Cheriff A, Cole CL, Bunce A, Ash J, Kaushal R. Physician experiences transitioning between an older versus newer electronic health record for electronic prescribing. Int J Med Inform 2012; 81(8): 539-548.

12. Abramson EL, Malhotra S, Osorio SN, Edwards A, Cheriff A, Cole C, Kaushal R. A long-term follow-up evaluation of electronic health record prescribing safety. J Am Med Inform Assoc 2013; 20(e1): e52-e58.

13. Grossman JM, Gerland A, Reed MC, Fahlman C. Physicians' experiences using commercial e-prescribing systems. Health Aff (Millwood) 2007; 26: w393-404.

14. Crosson JC, Isaacson N, Lancaster D, McDonald EA, Schueth AJ, DiCicco-Bloom B, Newman JL, Wang CJ, Bell DS. Variation in electronic prescribing implementation among twelve ambulatory practices. J Gen Intern Med 2008; 23: 364-371.

15. Wang CJ, Patel MH, Schueth AJ, Bradley M, Wu S, Crosson JC, Glassman PA, Bell DS. Perceptions of standards-based electronic prescribing systems as implemented in outpatient primary care: a physician survey. J Am Med Inform Assoc 2009; 16: 493-502.

16. Weingart SN, Massagli M, Cyrulik A, Isaac T, Morway L, Sands DZ, Weissman JS. Assessing the value of electronic prescribing in ambulatory care: a focus group study. Int J Med Inform 2009; 78:571-578.

17.Lapane KL, Rosen RK, Dube C. Perceptions of e-prescribing efficiencies and inefficiencies in ambulatory care. Int J Med Inform 2011; 80: 39-46.

18. Makam AN, Lanham HJ, Batchelor K, Samal L, Moran B, Howell-Stampley T, Kirk L, Cherukuri M, Santini N, Leykum LK, Halm EA. Use and satisfaction with key functions of a common commercial electronic health record: a survey of primary care providers. BMC Med Inform Decis Mak 2013; 13: 86.

19. Hanauer DA, Branford GL, Greenberg G, Kileny S, Couper MP, Zheng K, Choi SW. Two-year longitudinal assessment of physicians' perceptions after replacement of a longstanding homegrown electronic health record: does a J-curve of satisfaction really exist? J Am Med Inform Assoc 2016; e-pub ahead of print.

20.Zandieh SO, Abramson EL, Pfoh ER, Yoon-Flannery K, Edwards A, Kaushal R. Transitioning between ambulatory EHRs: a study of practitioners' perspectives. J Am Med Inform Assoc 2012; 19: 401-406.

21.Pfoh ER, Abramson E, Zandieh S, Edwards A, Kaushal R. Satisfaction after the transition between electronic health record systems at six ambulatory practices. J Eval Clin Pract 2012; 18(6): 1133-1139.

22. Strauss AC, Juliet. Basics of Qualitative Research: Techniques and Procedures for Developing Grounded Theory. 2nd ed. Thousand Oaks, CA: Sage Publications, Inc. 1998.

23. Glaser B. The Constant Comparative Method of Qualitative Analysis. Grounded Theory Review 2008; 07. 
24. Fleming NS, Becker ER, Culler SD, Cheng D, McCorkle R, da Graca B, Ballard DJ. The impact of electronic health records on workflow and financial measures in primary care practices. Health Serv Res 2014; 49: 405-420.

25. Terry AL, Brown JB, Bestard Denomme L, Thind A, Stewart M. Perspectives on electronic medical record implementation after two years of use in primary health care practice. J Am Board Fam Med 2012; 25: 522-527.

26. McAlearney AS, Hefner JL, Sieck C, Rizer M, Huerta TR. Evidence-based management of ambulatory electronic health record system implementation: an assessment of conceptual support and qualitative evidence. Int J Med Inform 2014; 83: 484-494.

27. McAlearney AS, Hefner JL, Sieck CJ, Huerta TR: The Journey through Grief: Insights from a Qualitative Study of Electronic Health Record Implementation. Health Serv Res 2015; 50(2): 462-488.

28. Lee F, Teich JM, Spurr CD, Bates DW. Implementation of physician order entry: user satisfaction and selfreported usage patterns. J Am Med Inform Assoc 1996; 3: 42-55.

29. Ash JS, Sittig DF, Seshadri V, Dykstra RH, Carpenter JD, Stavri PZ. Adding insight: a qualitative cross-site study of physician order entry. Int J Med Inform 2005; 74: 623-628.

30. Bates DW, Kuperman GJ, Wang S, Gandhi T, Kittler A, Volk L, Spurr C, Khorasani R, Tanasijevic M, Middleton B. Ten commandments for effective clinical decision support: making the practice of evidencebased medicine a reality. J Am Med Inform Assoc 2003; 10: 523-530.

31. Middleton B, Bloomrosen M, Dente MA, Hashmat B, Koppel R, Overhage JM, Payne TH, Rosenbloom ST, Weaver C, Zhang J. Enhancing patient safety and quality of care by improving the usability of electronic health record systems: recommendations from AMIA. J Am Med Inform Assoc 2013; e1: e2-e8.

32. Bramble JD, Abbott AA, Fuji KT, Paschal KA, Siracuse MV, Galt K. Patient safety perspectives of providers and nurses: the experience of a rural ambulatory care practice using an EHR with E-prescribing. J Rural Health 2013; 29: 383-391.

33. Nanji KC, Slight SP, Seger DL, Cho I, Fiskio JM, Redden LM, Volk LA, Bates DW. Overrides of medication-related clinical decision support alerts in outpatients. J Am Med Inform Assoc 2014; 21: 487-491.

34. Shah NR, Seger AC, Seger DL, Fiskio JM, Kuperman GJ, Blumenfeld B, Recklet EG, Bates DW, Gandhi TK. Improving acceptance of computerized prescribing alerts in ambulatory care. J Am Med Inform Assoc 2006; 13: 5-11.

35.van der Sijs H, Aarts J, Vulto A, Berg M. Overriding of drug safety alerts in computerized physician order entry. J Am Med Inform Assoc 2006; 13: 138-147.

36. Phansalkar S, van der Sijs H, Tucker AD, Desai AA, Bell DS, Teich JM, Middleton B, Bates DW. Drug-drug interactions that should be non-interruptive in order to reduce alert fatigue in electronic health records. J Am Med Inform Assoc 2013; 20: 489-493.

37. Phansalkar S, Desai A, Choksi A, Yoshida E, Doole J, Czochanski M, Tucker AD, Middleton B, Bell D, Bates DW. Criteria for assessing high-priority drug-drug interactions for clinical decision support in electronic health records. BMC Med Inform Decis Mak 2013; 13: 65.

38. Phansalkar S, Zachariah M, Seidling HM, Mendes C, Volk L, Bates DW. Evaluation of medication alerts in electronic health records for compliance with human factors principles. J Am Med Inform Assoc 2014; 21: e332-340.

39. Institute of Medicine: Health IT and Patient Safety: Building Safer Systems for Better Care. Washington, DC 2012.

40. Reider J. "Usability of EHRs remains a priority for ONC" 2014. http://www.healthit.gov/buzz-blog/elec tronic-health-and-medical-records/usability-ehrs-remains-priority-onc/. Access date September 2, 2016.

41.Lynch K, Kendall M, Shanks K, Haque A, Jones E, Wanis MG, Furukawa M, Mostashari F. The Health IT Regional Extension Center Program: evolution and lessons for health care transformation. Health Serv Res 2014; 49: 421-437.

42.Boas SJ, Bishop TF, Ryan AM, Shih SC, Casalino LP. Electronic health records and technical assistance to improve quality of primary care: Lessons for regional extension centers. Healthc (Amst) 2014; 2: 103-106. 